\title{
8 Die drei großen Meta-Fragen der Herkulanischen Papyrologie
}

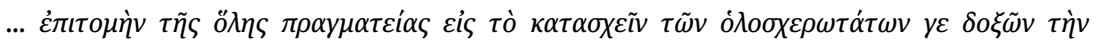

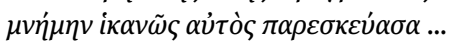

Epikur, Herodotbrief (D.L. 10,35)

Nun kristallisierten sich in den letzten zwei Jahrzehnten einige Dauerfragen oder übergeordnete Punkte der Herkulanischen Papyrologie heraus, welche ich hier erstmals expressis verbis als die drei großen „Meta-Fragen“ kategorisieren und zusammenfassen will.

1. Soll weiter in der Villa gegraben und ggf. gezielt nach weiteren Rollen gesucht werden?

Wie sollte dies geschehen? Ist eine lateinische und nicht-epikureische (griechische) Sektion der Bibliothek womöglich noch unentdeckt?

2. Welches textuelle Potential haben die schon geöffneten Papyri durch die Anwendung neuer Bildgebungsverfahren?

Wie defizitär sind ältere Ausgaben? Welche modernen Bildgebungsverfahren zum Lesen aufgerollter Papyri wurden und werden angewandt? Wie viele Papyri sind schon geöffnet, wurden aber noch niemals ediert?

3. Kann man die hunderte Rollen und Rollenteile, welche heute noch unaufgewickelt in der Sammlung liegen, mit modernen Techniken öffnen oder ihren Text lesbar machen?

Wenn ja, mit welchen Methoden und bis wann? Ist die Menge an noch unaufgewickeltem Text genauer quantifizierbar? 